This item was submitted to Loughborough's Research Repository by the author.

Items in Figshare are protected by copyright, with all rights reserved, unless otherwise indicated.

\title{
Study of the phase-varying mechanisms of ion current signals for combustion phasing in a gasoline $\mathrm{HCCl}$ engine
}

PLEASE CITE THE PUBLISHED VERSION

http://dx.doi.org/10.1016/j.fuel.2013.05.040

\section{PUBLISHER}

(c) Elsevier

\section{VERSION}

VoR (Version of Record)

\section{PUBLISHER STATEMENT}

This work is made available according to the conditions of the Creative Commons Attribution-NonCommercialNoDerivatives 4.0 International (CC BY-NC-ND 4.0) licence. Full details of this licence are available at: https://creativecommons.org/licenses/by-nc-nd/4.0/

\section{LICENCE}

CC BY-NC-ND 4.0

\section{REPOSITORY RECORD}

Dong, Guangyu, Liguang Li, Zhijun Wu, Zhiyong Zhang, and Dezong Zhao. 2017. "Study of the Phase-varying Mechanisms of lon Current Signals for Combustion Phasing in a Gasoline HCCl Engine”. figshare. https://hdl.handle.net/2134/26512. 


\title{
Study on the gasoline flame ionization mechanism and ion current phase variation for HCCI combustion phasing
}

\author{
Guangyu Dong, ${ }^{\mathrm{a}, *}$, Liguang $\mathrm{Li}^{\mathrm{a}}$, Zhijun $\mathrm{Wu}^{\mathrm{a}}$, Zhiyong Zhang ${ }^{\mathrm{a}}$, Dezong Zhao ${ }^{\mathrm{b}}$ \\ ${ }^{a}$ School of Automotive Studies, Tongji University, Shanghai, 201804, China \\ ${ }^{b}$ Department of Aeronautical and Automotive Engineering, Loughborough University, Loughborough, LE11 $3 T U$, UK
}

\begin{abstract}
In this paper, the gasoline flame ionization mechanism and the phase variation of the ion current signal were investigated to understand the mechanism of ion current based HCCI combustion phasing.A kinetic model was developed to analyze the ion current formation and recombination process by coupling gasoline flame ionization mechanism with engine combustion model. The modeling results indicated that on the tested $\mathrm{HCCI}$ engine, the production rate of $\mathrm{H}_{3} \mathrm{O}^{+}$ions is nearly third order with respect to the concentration of air fuel mixtures, and it is also increased when the intake temperature rises. During the ion recombination process, numerically the $\mathrm{H}_{3} \mathrm{O}^{+}$ recombination rate can be regarded as second order with respect to its concentration. Due to the above affecting mechanism, the phase varying tendency of the ion current signals is as same as the heat release curves, but the phase offsets between them varies under different combustion boundary conditions. The calculation results from the multi-zone model indicates that the $\mathrm{H}_{3} \mathrm{O}^{+}$ formation rate is decreased in each zone under leaner fuel concentration conditions, while the ion recombination rate is decreased more significantly because its second order relationship with the ion concentration. Then $\mathrm{dI}_{\max }$, the crank angle position with maximum ion production rate, was appeared even later comparing to $\mathrm{H}_{\max }$, the position where the maximum heat release rate occurred. Besides, a larger phase offset between $\mathrm{dI}_{\max }$ and the $\mathrm{H}_{\max }$ under lower intake temperature conditions was also observed, and can be well predicted by the modeling result.
\end{abstract}

Keywords: HCCI, phase difference, ion current, flame ionization mechanism

\footnotetext{
${ }^{*}$ Corresponding author

Email address: g.dong@lboro.ac.uk (Guangyu Dong )
} 


\section{Introduction}

HCCI has attracted much interest in ICE combustion research during the last decade due to its high fuel economy performance and low NOx emissions [25, 7]. However, the combustion phasing control of HCCI engine has become the bottleneck for its application in productive engines [20, 19]. Since straightforward methods to control combustion process, like spark ignition or fuel injection, are unavailable on HCCI engine, the consideration of robustness makes closed loop control methods on combustion necessary. Accordingly, combustion sensing and feedback control became the key issues in solving this problem $[9,23]$.

Ion sensing technology gradually proved to be one of the most promising approaches for HCCI combustion phasing in mass production engines $[14,15]$. In mass productive engines, either the spark plug or the heating plug can be used as the sensor to measure the ion current signals without modifying the engine structure. Therefore, the technique has been widely investigated nowadays because of its low cost and easy maintenance.

Many literatures have reported that there is a certain correlation between the phase of ion current signals and heat release curves within a large range of engine operation conditions $[13,16,1]$. The variation of the phase difference between them was gradually noticed on HCCI engines recently. Andreas et. al. [22] found that in the methanol HCCI engine, regardless of the ion sensor locations, the phase difference between the ion50 (crank angle for 50\% of maximum ion current amplitude) and the CA50 (crank angle for 50\% Burned Mass Fraction) is increased up to 10 crank angle degrees when the fuel concentration decreased. Martin and Ingemar [11] indicated that the motion of air fuel mixtures also significantly affected the waveform of ion current, but statistically the varying tendency of the phase difference between ion50 and CA50 is unaffected, and this phase difference will be enlarged under low equivalence ratio conditions. The above studies indicated that the effects from the physical aspects of ion sensing system are not the source of such a variation about phase difference. On the other hand, the study from Wu [24] also suggested that the electrode parameters including the polarity, size, and distance do little influence on the ionization current waveform. Hence, the inherent kinetics of ion current formation process should be studied as the key to understand the phase difference between these two signals. 
Table 1: Specifications of the Test Engine

\begin{tabular}{llll}
\hline Cylinder diameter $/ \mathrm{mm}$ & 95 & IVO $\left({ }^{\circ} \mathrm{CA}\right)$ & 47 BTDC \\
Piston Stroke $/ \mathrm{mm}$ & 114 & IVC $\left({ }^{\circ} \mathrm{CA}\right)$ & 35 ATDC \\
Compression ratio & 12.85 & EVO $\left({ }^{\circ} \mathrm{CA}\right)$ & 30 BTDC \\
Intake temperature $/ \mathrm{K}$ & $298-600$ & EVC $\left({ }^{\circ} \mathrm{CA}\right)$ & 46 ATDC \\
Engine speed $/ \mathrm{rpm}$ & 1200 & Fuel & gasoline $(97 \#)$ \\
\hline
\end{tabular}

The flame chemi-ionization mechanism has been studied for a long time. In 1950s, some studies were conducted for the identification of the ions aroused in hydrocarbon flame $[3,6]$. Later, the initial analysis about the ion generation rates was accomplished by Weinberg and Lawton [18, 12]. For the study of soot formation process, a mechanism for flame ionization process was proposed by Warnatz [21]. The ionic structure and primary ions in low temperature laminar flame was also studied based on mass spectrometry analysis by Fialkov [8]. Recently, for achieving an ion current signal based combustion phasing on HCCI engines, the amplitude varying principles of the ion current signal were studied by Bogin and Dibble via applying an ion production mechanism with a well mixed reactor model [2].

In this paper, a kinetic model was developed to achieve a mechanism level understanding of the phase correlation between the ion current signal and the heat release curve. A multizone combustion model coupled with a gasoline flame ionization mechanism was constructed in this paper. Through the mechanism analysis, the varying principles of the ion production and recombination process were investigated. Furthermore, the effect of both the fuel concentration and the intake temperature on ion production process were discussed based on the model predictions and the experimental results. All this work would contribute to the vital issue of ion sensing based combustion phasing on HCCI engines.

\section{Experimental set-up and methods}

The test engine was a modified $0.8 \mathrm{~L}$ single cylinder diesel engine. The engine specifications are listed in Table 1 . One $8 \mathrm{~kW}$ external heater was installed onto the intake air path to adjust the intake temperature. The ion current detection system is shown in Figure 1. The engine block was connected to the positive electrode of the DC power source. A spark plug was installed on 


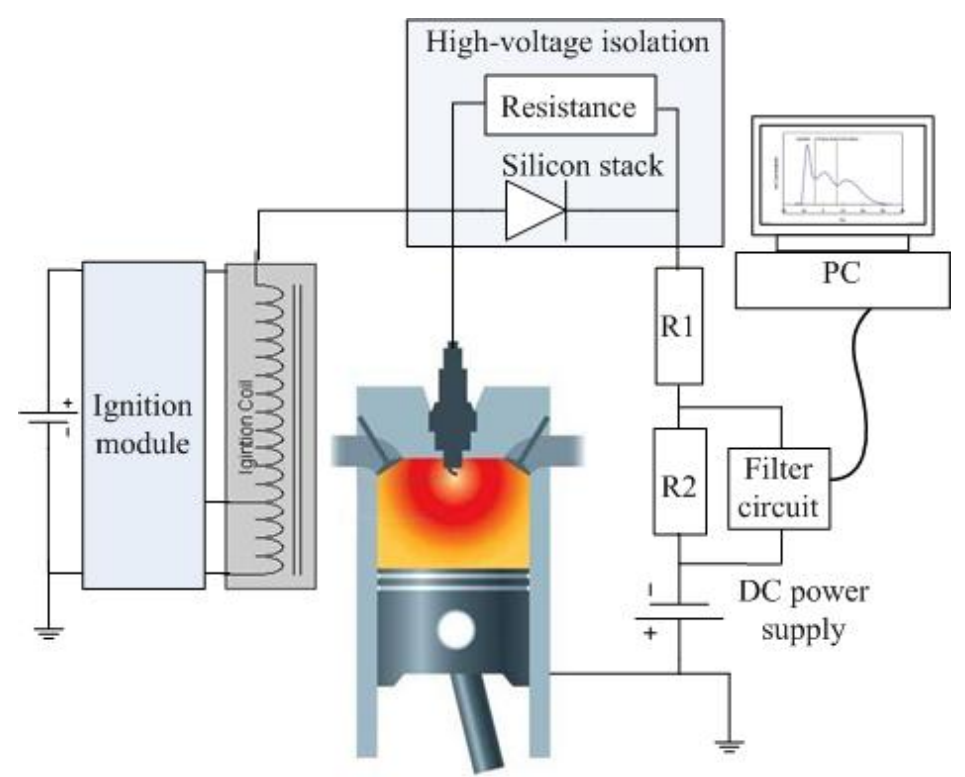

Figure 1: Schematic configuration of the ion current sensing system

the cylinder head as the ion-sensor. A $270 \mathrm{~V}$ bias DC voltage was used for arousing the ion current signal.

The ion current signal, cylinder pressure, intake temperature/pressure and other parameters are all collected through analog and digital ports of high-speed data acquisition card after corresponding modulation.

\section{Fundamentals}

\subsection{Skeleton Ion Formation Mechanism}

In this paper, a skeleton chemical kinetics mechanism including 9 varieties of ion components $\left(\mathrm{C}_{2} \mathrm{H}_{3} \mathrm{O}^{+}, \mathrm{C}_{3} \mathrm{H}_{3}^{+}, \mathrm{CH}_{3}^{+}, \mathrm{CHO}^{+}, \mathrm{O}^{+}, \mathrm{OH}^{+}, \mathrm{H}_{3} \mathrm{O}^{+}, \mathrm{O}_{2}^{+}, \mathrm{e}\right)$ and 28 steps of ion reactions was constructed based on previous studies $[4,5]$. The primary reaction approaches introduced are shown in Table 2. These reactions focus on the formation and recombination process of $\mathrm{H}_{3} \mathrm{O}^{+}$as the main ion species [17]. Reaction step 1-5 represent the key ion formation steps during the ionization process, while reaction step 6-9 describe the ion recombination mechanism. Hence, the variation principles of ion formatting history can be analyzed through above mechanism. 
Table 2: Primary reactions in the skeleton ion formation mechanism

\begin{tabular}{lllll}
\hline Step & Reaction & $\alpha /\left(\mathrm{m} \cdot(\mathrm{mol} \cdot \mathrm{s})^{-1}\right)$ & $\beta$ & $E_{a}\left(\mathrm{~kJ}^{-1} \mathrm{~mol}^{-1}\right)$ \\
\hline 1 & $\mathrm{CH}+\mathrm{O} \rightarrow \mathrm{CHO}^{+}+\mathrm{e}^{-}$ & $2.512 \cdot 10^{11}$ & 0 & 7.118 \\
2 & $\mathrm{CHO}^{+}+\mathrm{H}_{2} \mathrm{O} \rightarrow \mathrm{H}_{3} \mathrm{O}^{+}+\mathrm{CO}$ & $1.00 \cdot 10^{14}$ & -0.09 & 0 \\
3 & $\mathrm{CHO}^{+}+\mathrm{CH}_{2} \rightarrow \mathrm{CH}_{3}^{+}+\mathrm{CO}$ & $5.62 \cdot 10^{12}$ & 0 & 0 \\
4 & $\mathrm{CH}_{3}^{+}+\mathrm{C}_{2} \mathrm{H}_{2} \rightarrow \mathrm{C}_{3} \mathrm{H}_{3}^{+}+\mathrm{H}_{2}$ & $6.17 \cdot 10^{12}$ & 0 & 0 \\
5 & $\mathrm{CH}_{3}^{+}+\mathrm{H}_{2} \mathrm{O} \rightarrow \mathrm{C}_{2} \mathrm{H}_{3} \mathrm{O}^{+}+\mathrm{CH}_{2}$ & $7.24 \cdot 10^{12}$ & 0 & 0 \\
6 & $\mathrm{C}_{2} \mathrm{H}_{3} \mathrm{O}^{+}+\mathrm{e}^{-} \rightarrow \mathrm{CH}_{2} \mathrm{CO}+\mathrm{H}$ & $2.29 \cdot 10^{16}$ & -0.5 & 0 \\
7 & $\mathrm{H}_{3} \mathrm{O}^{+}+\mathrm{e}^{-} \rightarrow \mathrm{H}_{2} \mathrm{O}+\mathrm{H}$ & $2.29 \cdot 10^{16}$ & -0.5 & 0 \\
8 & $\mathrm{H}_{3} \mathrm{O}^{+}+\mathrm{e}^{-} \rightarrow \mathrm{OH}+\mathrm{H}+\mathrm{H}$ & $7.95 \cdot 10^{19}$ & -1.37 & 0 \\
9 & $\mathrm{CHO}^{+}+\mathrm{e}^{-} \rightarrow \mathrm{CO}+\mathrm{H}$ & $1.33 \cdot 10^{15}$ & 0 & 0 \\
\hline
\end{tabular}

\subsection{Numerical Model for HCCI Combustion}

To achieve a detailed analysis of gasoline flame ionization mechanism, the constructed skeleton ion formation mechanism was coupled with a reduced primary reference fuel (PRF) oxidation kinetic mechanism. The reaction kinetics and thermodynamic database utilized in the mechanism are provided by Jerzembeck and Pitsch which contains 203 species and 1071 steps of reactions, the detailed information of the PRF oxidation mechanism can be found in literature [10]. The modeling predictions are carried out with the commercial chemical reaction kinetics analysis software CHEMKIN.

Concerning the engine model, both a single zone and a multi-zone HCCI combustion model were constructed for different purposes.In the single-zone model, the ion formation process was regarded as occurred simultaneously within the whole cylinder because the air fuel mixtures was assumed as absolutely homogeneous. Then the formation process can be treated as independent of the recombination process. Accordingly, to investigate the mechanism of these two process separately, the single zone model was applied in this paper. However, the single zone model can not clearly reflect the real combustion process due to the assumption of absolutely homogeneous. Hence, to analyze the HCCI combustion process, a multi-zone engine model was built as well.

As shown in Figure 2, within the multi-zone model, the entire cylinder is divided into seven inner core zones (zone 1-7), an outer core zone (zone 8), a boundary layer zone (zone 9), and a crevice zone with constant volume (zone 10). To define the initial parameters at the moment of the intake valve closing (IVC), the equivalence ratio was measured by a universal exhaust gas oxygen 


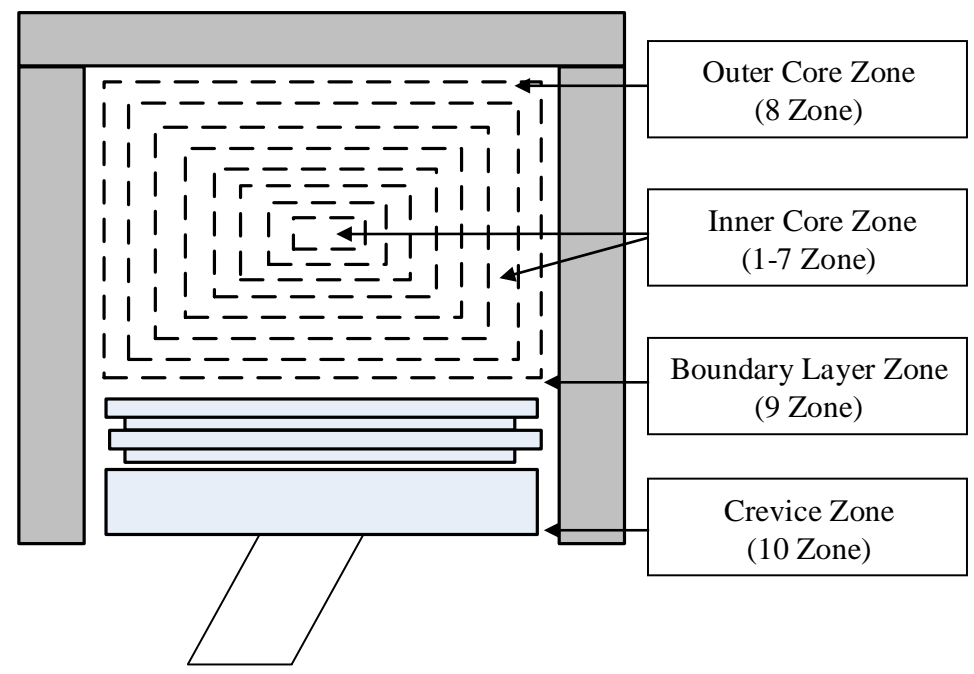

Figure 2: Schematic of the multi-zone HCCI combustion model

sensor. The average temperature and the residual gas fraction were calculated through the heat release analysis upon the cylinder pressure varying history.

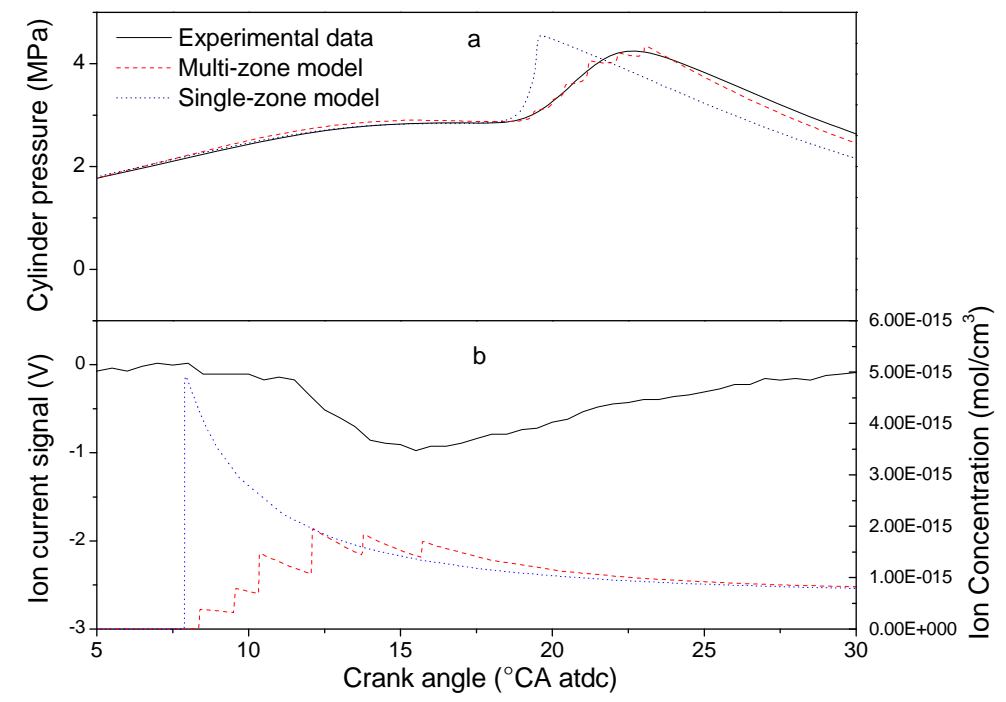

Figure 3: Predictions form single-zone, multi-zone and experimental results

A comparison between numerical predictions and experimental predictions is shown in Figure 3. Figure 3(a) indicates that the cylinder pressure predicted by the multi-zone model fits better with the experimental results comparing with the single-zone model. Also, as shown in Figure 3(b), the production history of $\mathrm{H}_{3} \mathrm{O}^{+}$was well demonstrated in the multi-zone model. The relationship between the modeling predicted ion production process and the ion current formatting process will 
be discussed later in this paper.

\section{Results and discussions}

\subsection{Affecting mechanism of ion formation process on HCCI engine}

The reactants concentration and temperature are dominating factors for both heat release process and ion formation process within a HCCI combustion event. Therefore, the effect of the equivalence ratio and the intake temperature $\left(T_{i n}\right)$ on the ion formation process is discussed in this paper.

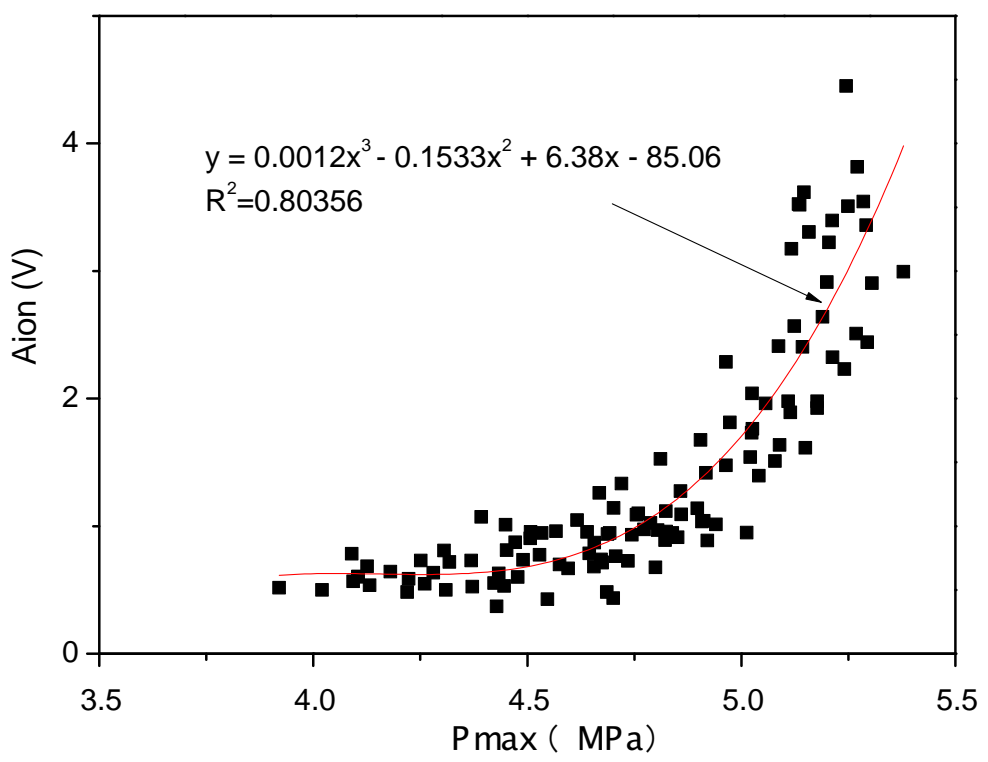

Figure 4: Relationship of peak cylinder pressures and ion current amplitudes

Under the condition of $448 \mathrm{~K}$ intake temperature and $0.092 \mathrm{MPa}$ intake pressure, the relationship between the amplitudes of ion current signal $\left(\mathrm{A}_{\text {ion }}\right)$ and the maximum cylinder pressure $\left(\mathrm{P}_{\max }\right)$ within the equivalence ratio range of $\Phi$ 0.3-0.44 is shown in Figure 4 . With the increase of air fuel concentration, the $\mathrm{P}_{\max }$ increased almost in a linear way, while the $\mathrm{A}_{\text {ion }}$ increased nearly as a third order polynomial function of $\mathrm{P}_{\max }$. In parallel, the concentration of produced $\mathrm{H}_{3} \mathrm{O}^{+}$ ions under different equivalence ratio was calculated through the signal-zone numerical model. As shown in Figure 5, the maximal concentration of $\mathrm{H}_{3} \mathrm{O}^{+}$ions is nearly third order respect to the equivalence ratio. Thus a conclusion can be drawn that the the amplitudes of ion current, which 


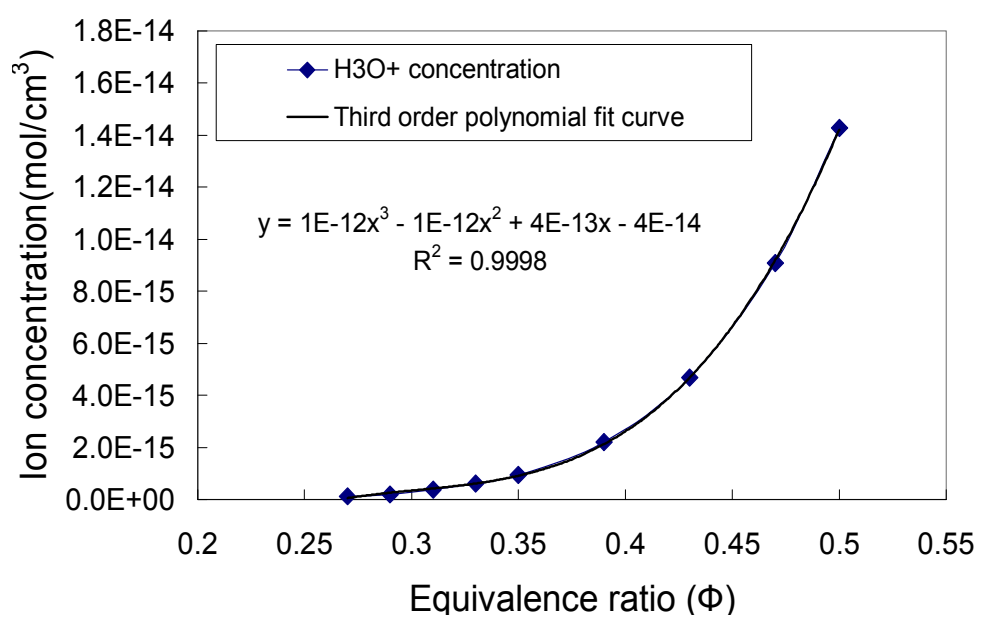

Figure 5: The relationship between the peaks of ion concentration and equivalence ratio

decided by the concentration of the $\mathrm{H}_{3} \mathrm{O}^{+}$, is nearly third order with respect to the concentration of air fuel mixtures on the test HCCI engine.

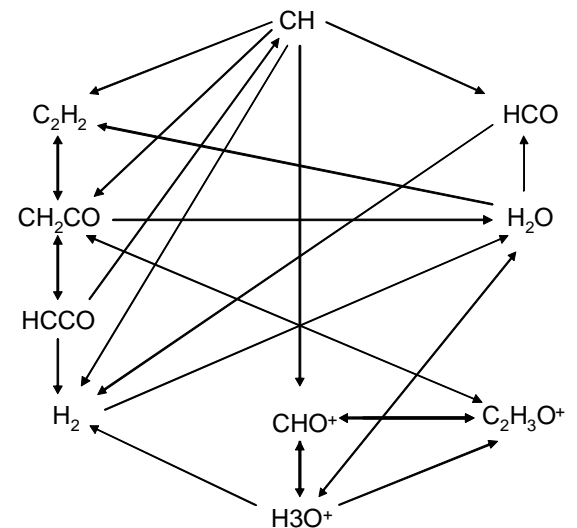

(a) Reaction path of $\mathrm{H}_{3} \mathrm{O}^{+}$ions

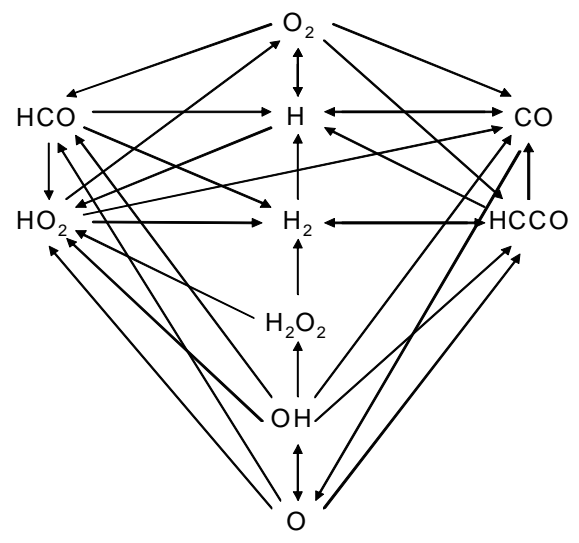

(b) Reaction path of $\mathrm{O}$ radicals

Figure 6: The reaction paths of dominate radicals and ions

To investigate such phenomena, a reaction path analysis was conducted. Figure 6(a) shows the results for 10 species that have the largest production rate during the $\mathrm{H}_{3} \mathrm{O}^{+}$ions formatting process. It can be seen that the chemi-ionization reaction is initiated by the reaction step of $\mathrm{CH}+\mathrm{O} \longrightarrow \mathrm{CHO}^{+}+\mathrm{e}^{-}$as $\mathrm{R}(1)$ in Table 2. Figure 6(b) shows the main reaction path of the $\mathrm{O}$ radical formatting process. The production of $\mathrm{O}$ radicals during the HCCI-type combustion process is triggered by the reaction of of $\mathrm{H}+\mathrm{O}_{2} \longrightarrow \mathrm{O}+\mathrm{OH}$. Through above reaction path diagram, it is clearly demonstrated that the concentration of both $\mathrm{CH}$ and $\mathrm{O}$ radicals are crucial 


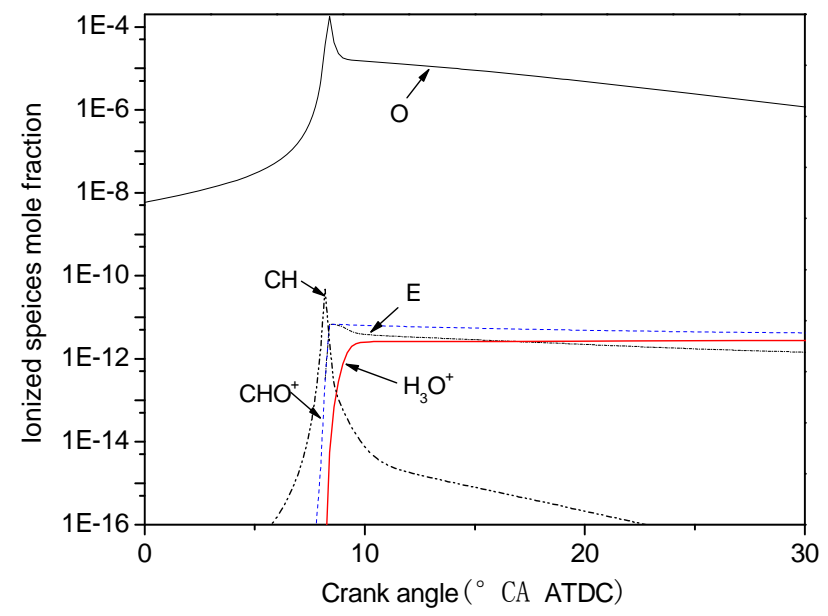

Figure 7: The concentration of dominate ions produced during the HCCI combustion

to the formatted ion concentration according to the Arrhenius equitation. However, as shown in Figure 7 , the concentration of $\mathrm{O}$ radical is almost 6 orders larger than the concentration of $\mathrm{CH}$ radicals during the high temperature reaction stage of HCCI combustion. Thus, it can be deduced that the concentration of $\mathrm{CH}$ is the dominate factor within the production process of $\mathrm{H}_{3} \mathrm{O}^{+}$ions. Then, due to the the production rate of $\mathrm{CH}$ radicals, the ion concentration is almost third order with respect to the equivalence ratio on the tested gasoline HCCI engine.

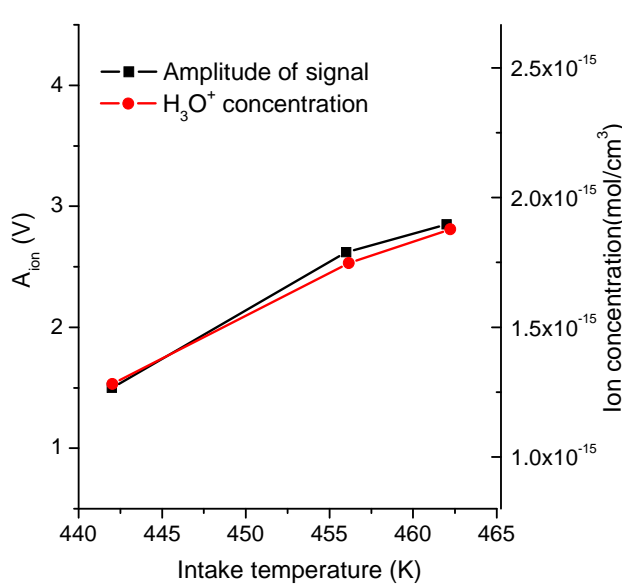

(a)

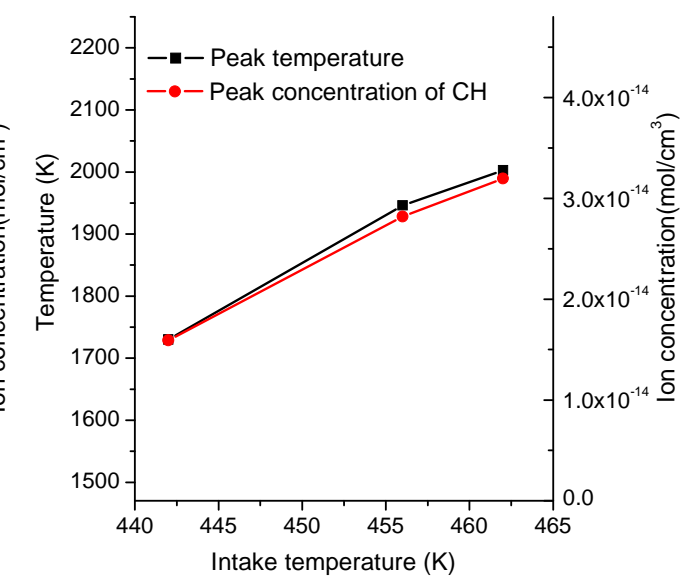

(b)

Figure 8: The concentration of $\mathrm{CH}$ and $\mathrm{H}_{3} \mathrm{O}^{+}$, and the peak combustion temperature under different $\mathrm{T}_{\text {in }}$ conditions

Concerning the ion formation process, the effect of intake temperature was also studied in this paper. With an equivalence ratio $\Phi=0.40$, the amplitudes of ion current signals and the peak 
$\mathrm{H}_{3} \mathrm{O}^{+}$concentration were observed as shown in Figure 8(a). When the intake temperature increased from $442 \mathrm{~K}$ to $462 \mathrm{~K}$, it can be seen that the calculated $\mathrm{H}_{3} \mathrm{O}^{+}$concentration and the amplitudes of ion current signal are increased in a similar way. Under a fixed equivalence ratio condition, the intake temperature will mainly affect the maximum temperature during the combustion process. As shown in Figure 8(b), with the increasing maximum combustion temperature, the concentration of $\mathrm{CH}$ radicals was increased as well. As mentioned above, the $\mathrm{H}_{3} \mathrm{O}^{+}$concentration is dominated by the $\mathrm{CH}$ radical production, so the $\mathrm{H}_{3} \mathrm{O}^{+}$production rate was increased as well under higher intake temperature conditions .

\subsection{Ion recombination process on HCCI engine}

Within the multi-zone model, the ion recombination processes in the zone in which the latest ion formatting process is occurred will still treated in a way similar with the single-zone model. For a clear demonstration of the ion recombination processes, the single-zone combustion model was applied for the study of ion recombination process as well.

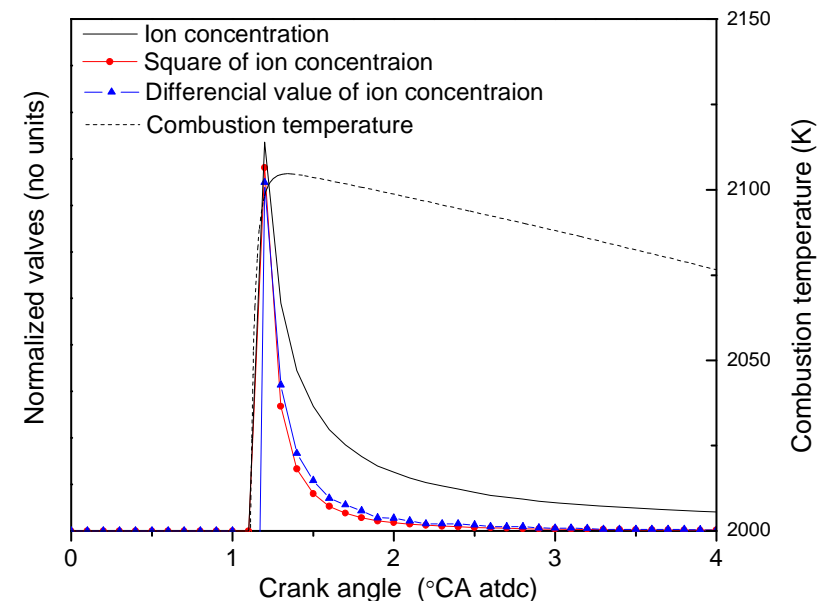

Figure 9: The eigenvalues of ion concentration and the combustion temperature

Under a wide range of air fuel concentration and intake temperature conditions which covers the operation range of the test HCCI engine $\left(0.22<\Phi<0.6,435 K<\mathrm{T}_{\text {in }}<465 \mathrm{~K}\right)$, a same variation principle of ion recombination process was found based on the modeling results. As shown in Figure 9, the concentration of $\mathrm{H}_{3} \mathrm{O}^{+}$, the square and differential value of $\mathrm{H}_{3} \mathrm{O}^{+}$concentration, were normalized into the same scale and compared to each other. Here the combustion temperature 
is also exhibited. It can be seen that once the heat release process finished, the varying tendency of the differential value is closed to the square value of ion concentration. Such phenomenon was appeared regardless of the changing of the boundary conditions. Therefore, the recombination rate of $\mathrm{H}_{3} \mathrm{O}^{+}$can be regarded as second order with respect to its concentration, or, reciprocally related to its concentration within the HCCI combustion process. Through the observation of the combustion temperature, it can be found that the drop of temperature was occurred as soon as the heat release process finished. This phenomenon is mainly because of the simplified position motion features in the single-zone model.

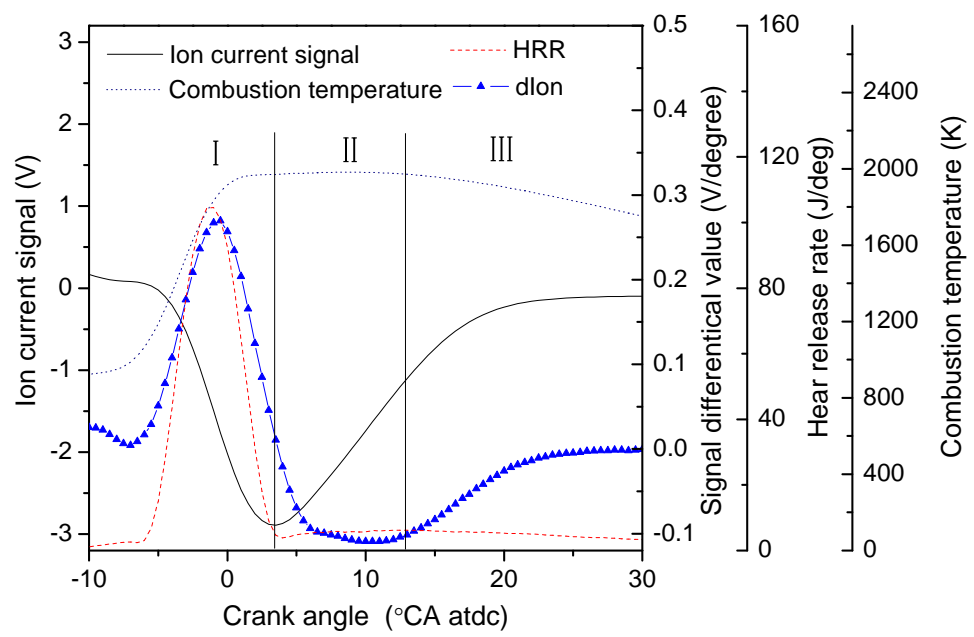

Figure 10: The original, differential and square values of the ion current signal (LPP closed to TDC)

Experimental work was also conducted for the observation of ion current signal falling process. Under the condition of intake temperature $\mathrm{T}_{\mathrm{in}}=465 \mathrm{~K}$ and equivalence ratio $\Phi=0.42$, the original ion current signal, combustion temperature, heat release curve and the differential value of ion current signal $\left(d_{\text {ion }}\right)$ are shown in Figure 10. Through the observation of the temperature variation and heat release process, the waveform of ion current signal was mainly departed into 3 stages. Stage I represented the ion current formatting process. Within this stage the ion current appeared and enhanced along with the heat release process. At the end of stage I, the ion current signal reached its peak amplitude and turned into falling process. According to the numerical analysis through the single-zone model, it can be predicted that the signal falling rate, indicated by the value of dIon, will proportional to the square of signal voltage once the combustion process finished. 
However, different from the modeling predictions, it can be seen that the signal falling rate in stage II was nearly kept as a constant value. The appearance of such phenomenon is mainly because that actually the ion formation process is mingled with the recombination process on the real engine. For the real combustion process, the air fuel mixture and the temperature distribution can not be treated as absolutely homogenous, and the ion formation can not be finished simultaneously within the whole cylinder. Thus, both the ion formation and the recombination mechanism were dominate within the stage II, and the ion concentration is not varied significantly in this stage.After the stage II, the piston moved away from the top dead center,the heat release process and the ion formation process were almost finished, then the decreasing rate of ion current signal was mainly decided by the ion recombination process. It can be seen that with the decrease of the ion concentration,the signal falling rate was decreased as well in stage III.

In order to understand the ion current signal falling tendency, the absolute value of ion current signal, the square value of the signal voltage $\left(S_{\text {ion }}\right)$ and the absolute value of the differential value of ion current signal $\left(\mathrm{d}_{\mathrm{ion}}\right)$, were normalized to same scale and compared with each other. As shown in Figure 11, the signal falling rate, indicated as the absolute value of $\mathrm{d}_{\mathrm{Ion}}$, correlated well with the square value of the signal intensity in stage III. Such phenomenon is consistent with the numerical predictions.

Keep test conditions the same, and reduce the intake temperature to $455 \mathrm{~K}$, the ion current

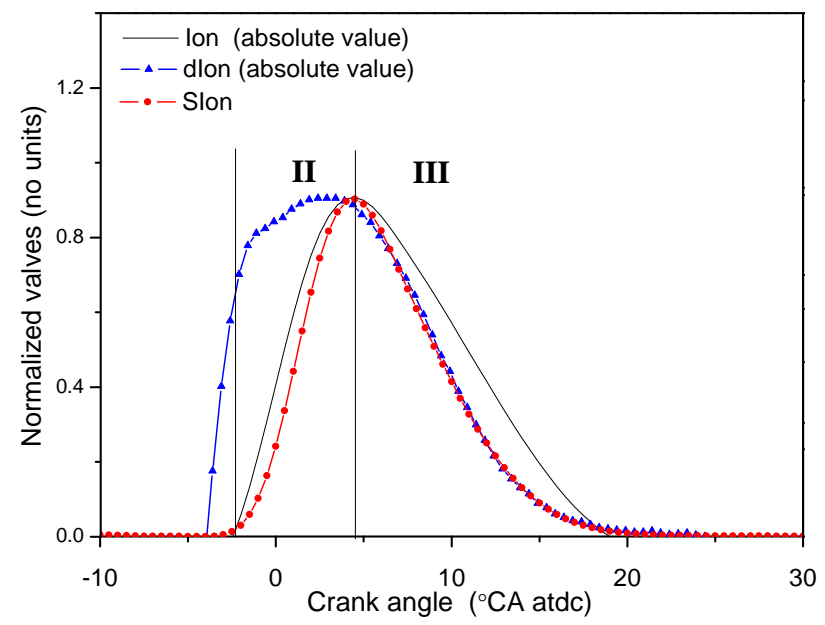

Figure 11: Comparison of ion current signal characteristics and combustion parameters 


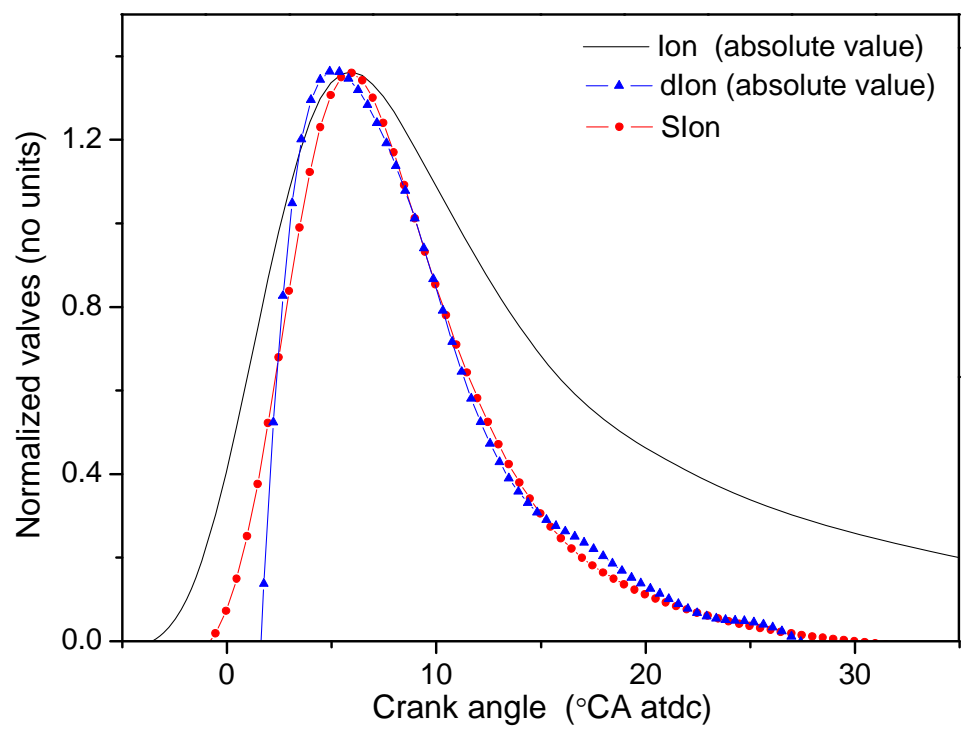

Figure 12: The original, differential and square values of ion current signal (LPP after TDC)

signal falling rate was also investigated. As shown in Figure 12, due to the decrease of the intake temperature, the combustion event occurred after the piston reaching top dead center. In such case, the in-cylinder gas expansion process can be regarded as adiabatic, and the normalized value of dIon is correlated with the normalized value of SIon during the whole falling process. Such phenomenon was also observed at lower intake temperature or leaner air fuel conditions. Thus, it can be deduced that the falling rate of ion current signal is significantly affected by the in-cylinder temperature; while within the adiabatic expansion process, the signal falling rate is second order respect to the signal intensity.

\subsection{Phase correlation between ion current signals and heat release curves}

For achieving a quantitative analysis about the phase correlation between ion current signals, calculated ion production processes and heat release processes, a set of the eigenvalues were defined as shown in Figure 13. As mentioned above, $\mathrm{H}_{\max }$, the crank position where the peak of heat release rate occurred was used as the indicator of combustion phase. Similarly, $\mathrm{P}_{\text {ion }}$, the position with maximum current intensity increasing rate, was defined to represent the phase of ion current signal. For the multi-zone model, the $\mathrm{H}_{3} \mathrm{O}^{+}$concentration was calculated within a series of discrete zones, and a number of peaks were appeared in the ion signal waveform. Hence, it is difficult to define the 


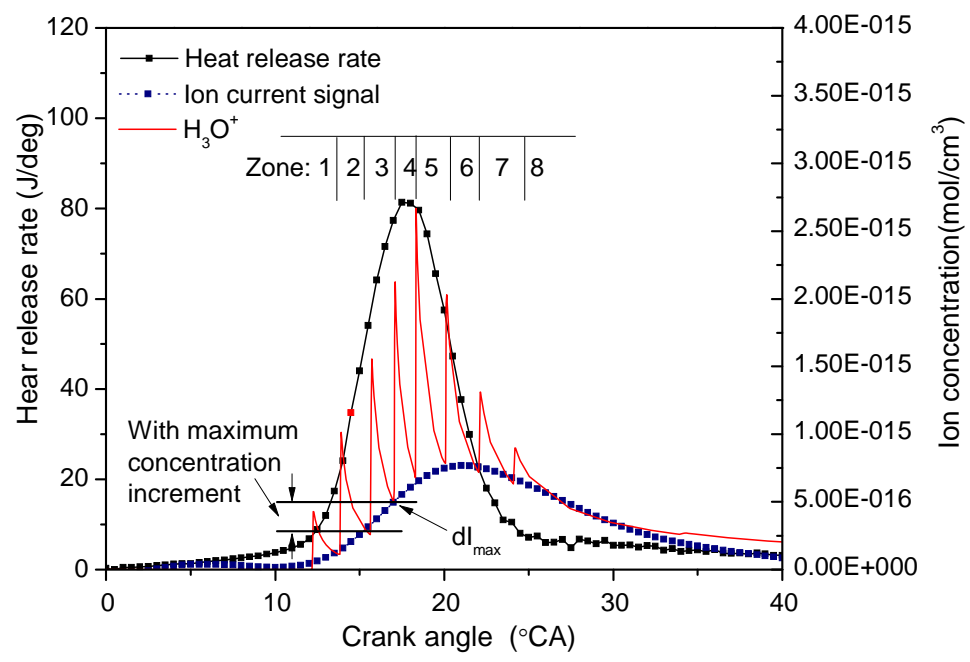

Figure 13: The eigenvalues abstract from ion concentration curve

phase of the ion production curves in multi-zone model. On the other hand, the air fuel mixture and temperature in each zone are regarded as absolutely homogenous like the situation in singlezone model, and the ion formation process is not mingled with the recombination process because of the instant ion production process. Therefore, the ion concentrations at the end of these zones were selected to represent a discrete ion concentration varying process since both ion formation and recombination process can be reflected by these selected values. Accordingly, the end point of the zone with highest ion concentration increment was defined as $\mathrm{dI}_{\max }$ to represent the phase of ion production curve.

Keeping the intake temperature at $448 \mathrm{~K}$, the waveforms of ion current, cylinder pressure, heat release process and ion formation process under different equivalence ratio conditions are shown in Figure 14. It can be seen that the cylinder pressure curves predicted by multi-zone model were correlated well with the experimental results. The mean square errors were contained less than 0.07 MPa under each condition. When the equivalence ratio $\Phi$ equaled to 0.44 , the phase offset between $\mathrm{dI}_{\max }$ and $\mathrm{H}_{\max }$ was $-0.15{ }^{\circ} \mathrm{CA}$. Mechanism analysis indicates that the ion concentration is nearly third order with respect to equivalence ration, and the recombination rate is numerically second order respect to the ion concentration. Accordingly, under rich air fuel concentration condition, the higher ion production rate will cause a higher ion recombination rate as well. Under such a equivalence ratio condition, both the heats release rate and ion production rate reach to their 

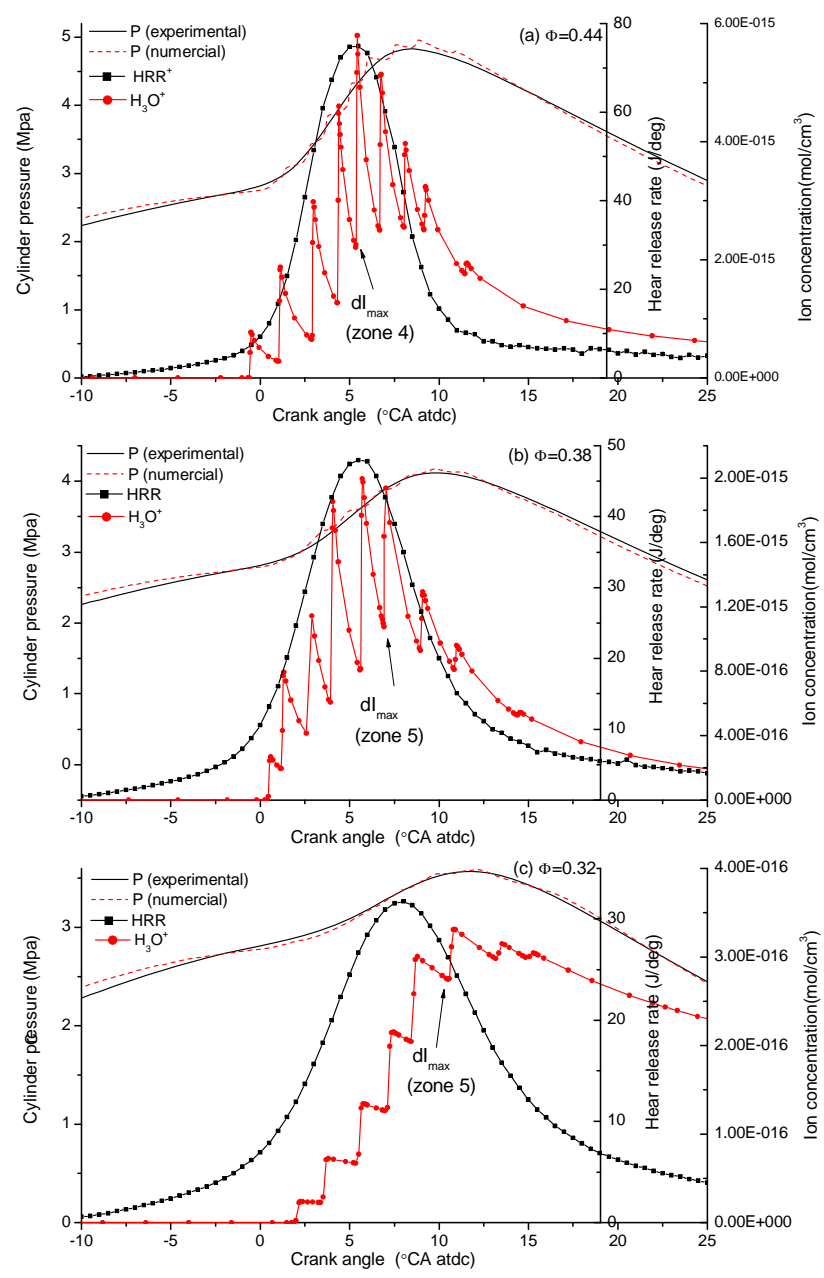

Figure 14: The waveforms of ion current, ion formation process and combustion parameters under different equivalence ratio conditions

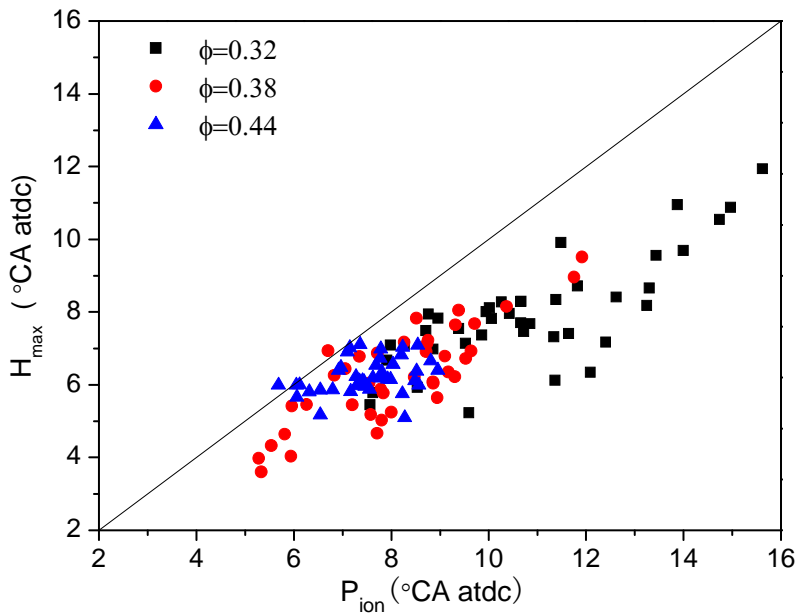

Figure 15: The phase difference between ion current signals and heat release curves $(\Phi 0.32-0.44)$ 

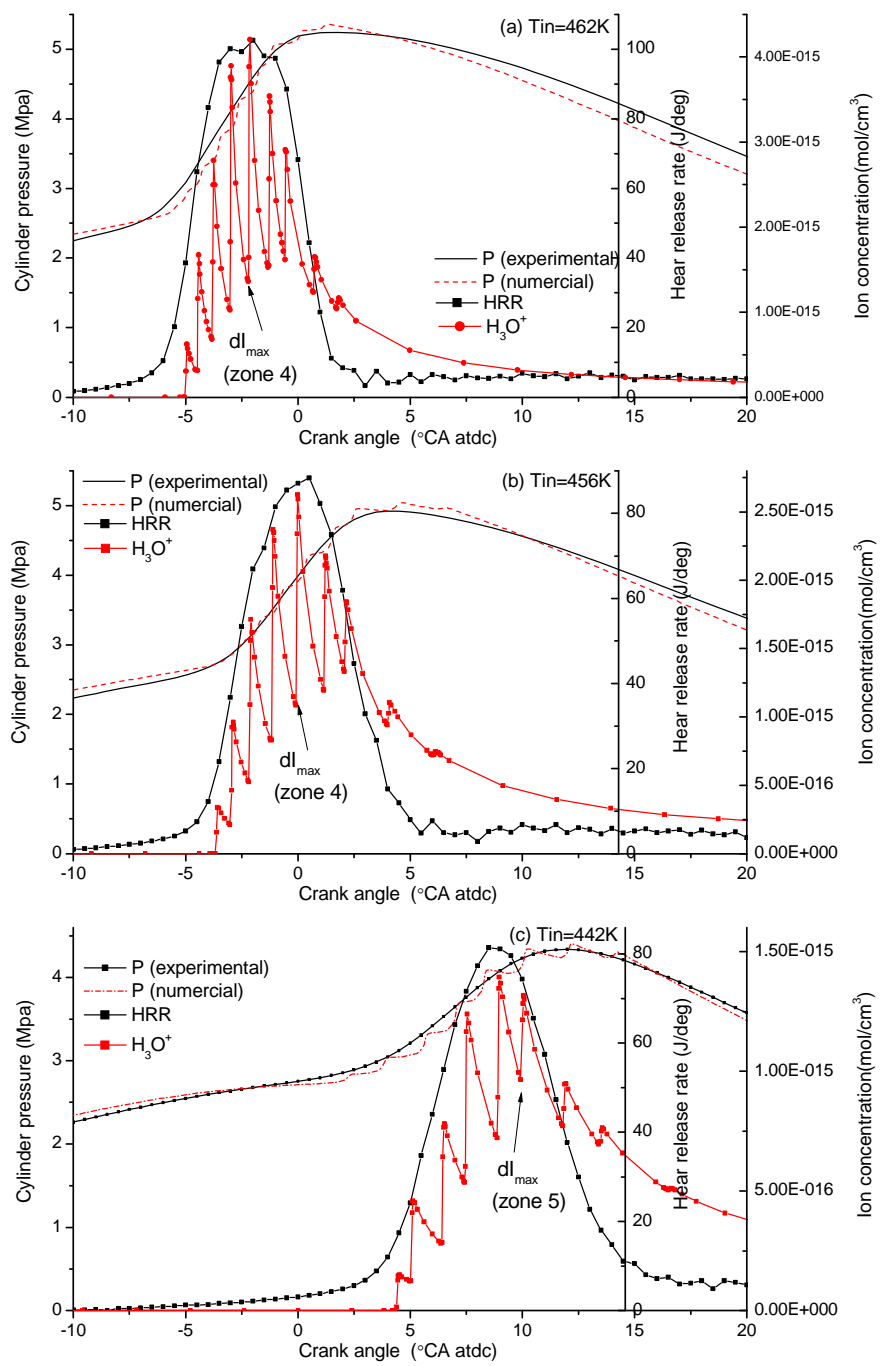

Figure 16: The waveforms of ion current, ion formation process and combustion parameters under different intake temperature conditions

maximum values in zone 5 , while the ion concentration increment in this zone was obviously reduced because of the ion recombination process. Actually the $\mathrm{dI}_{\max }$ was appeared in zone 4 and early than $\mathrm{H}_{\max }$. When the $\Phi$ decreased to 0.38 and 0.32 , it can be seen that the positions of $\mathrm{dI}_{\max }$ were retarded and appeared in zone 5. Also, the phase offset between $\mathrm{dI}_{\max }$ and $\mathrm{H}_{\max }$ are $1.3{ }^{\circ} \mathrm{CA}$ and $2.5{ }^{\circ} \mathrm{CA}$ respectively. This phenomenon implies that the decrease of ion recombination rate under lean air fuel concentration condition will increase the proportion of the ion production amount in the rear zone. Therefore, both $\mathrm{dI}_{\max }$ and $\mathrm{H}_{\max }$ will be retarded under lower fuel concentration conditions, while the position $\mathrm{dI}_{\max }$ will appeared even later compared to the $\mathrm{H}_{\max }$. In fact, the 
temperature and air fuel mixtures in each zone is still treated as absolute homogenous, so the calculated ion production process is faster than the real case. However, the numerical results still demonstrated that the phase offset between $\mathrm{dI}_{\max }$ and $\mathrm{H}_{\max }$ is not a fixed value, and this value will be enlarged under lean fuel concentration conditions. Maintaining the engine operation conditions the same as the settings in above simulation cases, the experimental results about the phase offset between $\mathrm{H}_{\max }$ and $\mathrm{P}_{\text {ion }}$ over 40 consecutive cycles were exhibited in Figure 15 . It can be seen that with the decreasing equivalence ratio, this phase offset were gradually increased. Quantities analysis indicated the averaged difference of $\mathrm{P}_{\text {ion }}-\mathrm{H}_{\max }$ increased from $1.4{ }^{\circ} \mathrm{CA}$ to $3.3^{\circ} \mathrm{CA}$ when the $\Phi$ decreased from 0.44 to 0.32 .

At a fixed equivalence ratio $(\Phi=0.4)$, the waveforms of ion current, cylinder pressure, heat release process and ion formation process under different intake temperature conditions are shown in Figure 16. Under the conditions of both $\mathrm{T}_{\mathrm{in}}=462 \mathrm{~K}$ and $\mathrm{T}_{\mathrm{in}}=458 \mathrm{~K}$, the positions of $\mathrm{dI}_{\max }$ are appeared in zone 4 and ahead of the $\mathrm{H}_{\max }$. While with an intake temperature of $448 \mathrm{~K}, \mathrm{dI}_{\max }$ was appeared in zone 5 and slightly later comparing to $\mathrm{H}_{\max }$. Such phenomenon indicates that the variation of intake temperature will affect the difference of $\mathrm{dI}_{\max }-\mathrm{H}_{\max }$ as well.

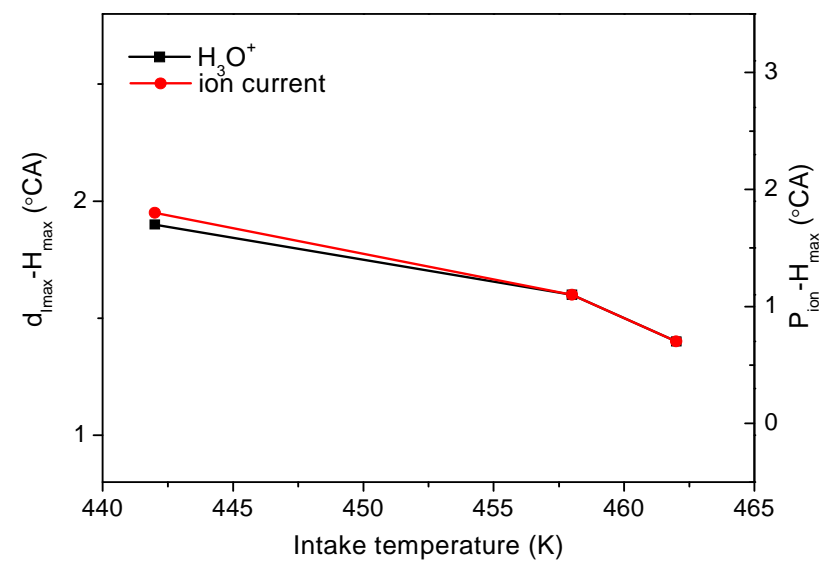

Figure 17: The phase difference between ion current signals and heat release curves $\left(\mathrm{T}_{\text {in }} 442-462 K\right)$

Figure 17 demonstrates the experimental results about the phase difference of $\mathrm{P}_{\text {ion }}-\mathrm{H}_{\max }$ under these conditions, it can be seen that the phase difference is slightly enlarged under the condition of $\mathrm{T}_{\mathrm{in}}=442 \mathrm{~K}$ although the combustion phase retarded significantly. As discussed above, the intake temperature also affects the ion formation process although not as obviously as air 
fuel concentration does. With the decreasing of the intake temperature, the ion formation rate decreased along with the peak combustion temperature. Accordingly, the ion recombination rate decreased due to the reduced ion concentration. Through the comparison between numerical and experimental results, a tendency still can be identified that the decreased ion recombination rate will enlarged phase difference between ion current signals and heat release curves under low $\mathrm{T}_{\text {in }}$ conditions.

\section{Conclusions}

Through coupling gasoline flame ionization mechanism with a multi-zone engine combustion model, a mechanism analysis of ionization current based HCCI combustion phasing was given. The key results presented in this paper are summarized as follows:

(1) On the test engine, the concentration of the $\mathrm{H}_{3} \mathrm{O}^{+}$ions aroused within the gasoline flame is strongly affected by the concentration of air fuel mixtures as it being nearly third order with respect to the equivalence ratio.

(2) For the ion recombination process, the recombination rate of $\mathrm{H}_{3} \mathrm{O}^{+}$is numerically second order respect to its own concentration. The increase of equivalence ratio or intake temperature will significantly enhance the ion recombination process due to the increased ion concentration.

(3) In the multi-zone model,the maximum ion formation rate will retard when the maximum heat release rate appeared later. As a sequence the ion recombination will also increases . Therefore, the location of the maximum ion current increasing rate and the maximum heat release rate varied with the same tendency.

(4) Comparing with the ion formation rates, the ion recombination rates reduced more significantly under the conditions of leaner equivalence ratios or lower intake temperatures. As a result, the maximum ion concentration increase rate will appear later comparing with the maximum heat release rate under such conditions. 


\section{Acknowledgement}

This work was supported by National Basic Research Priorities Program (973) of China under the grant reference of $2007 \mathrm{CB} 210005$.

[1] Ballester, J., Garcia-Armingol, T., 2010. Diagnostic techniques for the monitoring and control of practical flames. Progress in Energy and Combustion Science 36 (4), 375-411.

[2] Bogin, Gregory, J., Chen, J.-Y., Dibble, R. W., 2009. The effects of intake pressure, fuel concentration, and bias voltage on the detection of ions in a homogeneous charge compression ignition (hcci) engine. Proceedings of the Combustion Institute 32, 2877-2884.

[3] Calcote, H. F., 1957. Mechanisms for the formation of ions in flames. Combustion and Flame 1 (4), 385-403.

[4] Calcote, H. F., Keil, D. G., 1988. Ion-molecule reactions in sooting acetylene-oxygen flames. Combustion and Flame $74(2), 131-146$.

[5] Chung, T. H., 2009. Modeling positive ion current to a planar probe in low-pressure electronegative discharges. Physics of Plasmas $16(6)$.

[6] Deckers, J., Vantiggelen, A., 1957. Extraction of ions from a flame. Combustion and Flame 1 (3), 281-286.

[7] Dubreuil, A., Foucher, F., Mounaim-Rousselle, C., Dayma, G., Dagaut, P., 2007. Hcci combustion: effect of no in egr. Proceedings of the Combustion Institute 31, 2879-2886.

[8] Fialkov, A. B., 1997. Investigations on ions in flames. Progress in Energy and Combustion Science 23 (5-6), $399-528$

[9] Hamosfakidis, V., Im, H. G., Assanis, D. N., 2009. A regenerative multiple zone model for hcci combustion. Combustion and Flame 156 (4), 928-941.

[10] Jerzembeck, S., Glawe, C., Peters, N., 2009. Development and experimental evaluation of a high temperature mechanism for blended n-heptane-isooctane-ethanol-air-mixtures and gasoline-ethanol-air-mixtures, 78-83.

[11] Larsson, M., Denbratt, I., Koopmans, L., 2007. SAE Paper, 2007-01-0009.

[12] Lawton, J., Weinberg, F. J., 1964. Maximum ion currents from flames + maximum practical effects of applied electric fields. Proceedings of the Royal Society of London Series a-Mathematical and Physical Sciences 277 (1370), 468-497.

[13] Mehresh, P., Souder, J., Flowers, D., Riedel, U., Dibble, R. W., 2005. Combustion timing in hcci engines determined by ion-sensor: experimental and kinetic modeling. Proceedings of the Combustion Institute 30, $2701-2709$.

[14] Moudden, Y., Boubal, O., 2001. Indirect measurement of cylinder pressure peak position in an internal combustion engine. pp. $772-777$.

[15] Rivara, N., Dickinson, P. B., Shenton, A. T., 2009. A transient virtual-afr sensor using the in-cylinder ion current signal. Mechanical Systems and Signal Processing 23 (5), 1672-1682. 
[16] Saxena, S., Chen, J. Y., Dibble, R. W., 2011. Increasing the signal-to-noise ratio of sparkplug ion sensors through the addition of a potassium acetate fuel additive. Proceedings of the Combustion Institute 33, 3081-3088.

[17] Schaefer, B. A., 1984. The calculation of ion currents in hydrocarbon flames. Combustion and Flame 56 (1), $43-49$.

[18] Schneide.B, Weinberg, M. C., 1968. Electron-atom electron-molecule scattering functions from pseudopotentials. Bulletin of the American Physical Society 13 (2), 208-218.

[19] Shaver, G. M., Gerdes, J. C., Roelle, M., 2004. Physics-based closed-loop control of phasing, peak pressure and work output in HCCI engines utilizing variable valve actuation. pp. 150-155.

[20] Tanaka, S., Ayala, F., Keck, J. C., Heywood, J. B., 2003. Two-stage ignition in hcci combustion and hcci control by fuels and additives. Combustion and Flame 132 (1-2), 219-239.

[21] Thiele, M., Selle, S., Riedel, U., Warnatz, J., Maas, U., 2000. Numerical simulation of spark ignition including ionization. Proceedings of the Combustion Institute 28, 1177-1185.

[22] Vressner, A., Hultqvist, A., Hasegawa, R., 2005. SAE Paper, 2005-01-2093.

[23] Wang, Z., Wang, J.-X., Shuai, S.-J., Tian, G.-H., An, X. L., 2007. Experimental and computational studies on gasoline hcci combustion control using injection strategies. Journal of Engineering for Gas Turbines and Power-Transactions of the ASME 129 (3), 870-876.

[24] Wu, X., Gao, Z., Jiang, D., Huang, Z., 2008. Experimental investigation of the effect of electrodes on the ionization current during combustion. Energy \& Fuels 22 (5), 2941-2947.

[25] Yao, M., Zheng, Z., Liu, H., 2009. Progress and recent trends in homogeneous charge compression ignition (hcci) engines. Progress in Energy and Combustion Science 35 (5), 398-437. 